\title{
Bidirectional Network in Hybrid Coarse Wavelength Division Multiplexing/Time Division Multiplexing (CWDM/TDM) on NG-PON2 for 40 Gbps
}

\author{
Akhmad Hambali, Brian Pamukti * \\ School of Electrical Engineering \\ Telkom University \\ Telekomunikasi Street - 40257 \\ Bandung, Indonesia
}

\begin{abstract}
In this research, we propose hybrid Coarse Wavelength Division Multiplexing/Time Division Multiplexing (CWDM/TDM)Passive Optical Networks (PON) scheme for optimizing the new technology of Gigabit-PON (GPON) called Next GenerationPON Stage 2 (NG-PON2). The simulation of using this scheme proved that Q-Factor increase and Bit Error Rate (BER) decreased, significantly. We use CWDM scheme for downstream while TDM is used for upstream, and we assimilate both of them with new configuration in bidirectional cable setting. CWDM is used due to low nonlinearity effect like Kerr effects. It has the same working principle based on (Time Wavelength Division Multiplexing-PON) TWDM-PON by differentiating the use of wavelength, it can be easily implemented on existing PON technology, and can be used in single-mode optical fiber (SMF) with greater bandwidth and much cheaper operational costs. From the calculations and simulations, it can be analyzed that the network Hybrid of CWDM / TDM-PON able to work on bit rate of 40/10 Gbps on the number of users 32, 64, and 128, with Q-Factor value is above 6 equal to International Telecommunication Union of Telecommunication (ITU-T) standard. The number of users 32 with two cable lengths of 10 and $20 \mathrm{~km}$ have value of Q-Factor 25.960 and 14.815 respectively, while64 users with the same cable length have Q-Factor value of 15.808 and 13.046 respectively. In addition, 128 users with the same cable length have BER value of 17.778 and 12.944 respectively.
\end{abstract}

Keywords: CWDM, TDM, WDM-PON, 40G, NG-PON2.

\section{INTRODUCTION}

Passive Optical Network (PON) technology has been used by many operators in the world and continues to be developed to follow the needs of the internet with high speed and very large bandwidth. PON technology is chosen because it is considered to have low operating costs, very large bandwidth, and requires only passive components to connect between the central to the customer location [1]. One of the PON technology that is still developed is the Next-Generation Passive Optical Network stage 2 (NG-PON2). An organization called Full-Service Access Network (FSAN) is a developer of NG-PON2 technology. NG-PON2 can provide services with 40 Gbps downstream and 10 Gbps upstream using Time and Wavelength Division Multiplexed Passive Optical Network (TWDM-PON), that research has been done by [2] but only downstream side and improved DCF cable for dispersion compensating. Another research like [3] used frequency domain technique for reducing chromatic dispersion. Thus the researchers didn't analyze the upstream side.

Before FSAN decides to use TWDM-PON, there are two other options: Time-Division Multiplexing Passive Optical Network (TDM-PON) and Dense WavelengthDivision Multiplexing Passive Optical Network

\footnotetext{
* Corresponding Author.

Email: brianp@telkomuniversity.ac.id

Received: October 4, 2018 ; Revised: March 26, 2019

Accepted: April 15, 2019 ; Published: August 31, 2019

(C) 2019 PPET - LIPI
}

(DWDM-PON). TDM-PON is not used in NG-PON2 technology because in each Optical Network Termination (ONT) it must be fully operated at $40 \mathrm{Gbps}$ bit rate which causes too much bit rate to be used on every single user. DWDM-PON can support work on many wavelengths on one fiber, but FSAN did not use it on NG-PON2 technology because the price is too expensive.

The research about legacy of NG-PON2 has been performed by [4] that was comparing the generation of G-PON and NG-PON1 or XG-PON where NGPON1/XG-PON is a continuation of G-PON technology. While the NG-PON2 is the latest evolution of PON technology, where downstream bit rate increases to 40 Gbps and can be integrated with older GPON devices. In [5], the NG-PON2 with Arrayed Wave Guide (AWG) Multiplexing has been discussed. The researcher only used single length and did not use various length for analysis. Additionally, the writers used TWDM-DWDM scheme with eight wavelengths, and they found that system can not overcome the problem cost for vendors. Another research by [6] discussed about new technology of optical communication which has been analyzed with different modulation scheme.

Paper [7] describes NG-PON2 on standard section for new challenges. Several points show NG-PON2 has new scheme and technique to improve the communications network access. The most interesting part of thispaper is cyclic WDM that can be installed in NG-PON2. 
This research discusses efficiency of TDM-CWDM besides the standard of NG-PON2 with TWDM. We have simulated and analyzed the Combination of Coarse Wavelength Division Multiplexing Time Division Multiplexing (TWDM-PON Combination CWDM) with TWDM-PON basic method to be used on NG-PON2 technology with 40 Gbps downstream bit rate, and 10 Gbps upstream bit rate. The other parameters such as cable length and number of used splitters will affect the feasibility of the network used.

The contribution of this paper is the use of new configuration method of NG-PON2 that can be implemented as an alternative solution because of its similar working principle as TWDM-PON, but it is more efficient on its wavelength spacing. It can be easily implemented on existing PON technology, and can be used in single mode optical fiber (SMF) with large bandwidth and $40 \%$ much cheaper operating costs than others.

\section{METHODOLOGY}

\section{A. Measurement Method}

In this paper, there are many parameters that must be considered to analyze the system performance, namely Q-Factor and BER. The Q-Factor is a quality factor that will determine whether it has a good quality of communication or not. The larger $\mathrm{Q}$ value shows the greater difference and shows that the more noticeable difference between bits 0 and 1 clearly causes better bit detection. Q-Factor is related to the BER value which has a minimum value to be a measure of feasibility on the NG-PON system 2. The Q-Factor value used as a benchmark is Q-Factor $\geq 6$. The Q-Factor value is obtained from (1).

$$
Q=\frac{\mu 1-\mu 0}{\sigma 1-\sigma 0}
$$

where $\mu_{1}$ is level $1 \mathrm{bit}, \mu_{0}$ is level 0 bit, $\sigma_{l}$ is standard deviation for 1 bit and $\sigma_{0}$ is standard deviation for 0 bit.

Bit Error Rate (BER) is the comparison of the ratio between errors or damage bits with the bits sent throughout. The value of BER is a test that serves to predicts how many errors occur on the receiver side in each second. The description of the BER value can be calculated with the application of BER in the amount of $10^{-9}$, which indicates the magnitude of the possibility of reading errors on the receiving side of $10^{-9}$, or in other words in the $10^{9}$ sent, there is 1 bit that has a reading or reception error. The relationship between $\mathrm{Q}$ Factor and error probability $\left(P_{e}\right)$ or BER can be seen in (2) and (3).

$$
\begin{aligned}
& P_{e}=\frac{1}{2} \operatorname{erfc}\left(\frac{Q}{\sqrt{2}}\right), \\
& t_{s y s}=\sqrt{t_{T x}^{2}+t_{r x}^{2}+t_{m a t}^{2},}
\end{aligned}
$$

where $t_{T x}$ is rise time from the transmitter, $t_{R x}$ is rise time from the receiver, and $t_{m}$ is rise time from a medium (optical fiber). Refer to (4), the rise time in a medium is the multiplier effect from dispersion $\left(D_{m}\right)$, width spectral $(\Delta \sigma)$ and optical fiber length $(L)$.

$$
t_{m}=\Delta \sigma \times \mathrm{L} \times \mathrm{D}_{\mathrm{m}} .
$$

\section{B. Research Design}

Figure 1 describes the system modal of research. On the OLT side, there are two blocks, namely the transmitter block (sender) and receiver block (receiver). Transmitter on OLT uses a Pseudo-Random Bit Sequence (PRBS) Generator which generates stream data to be transmitted using Non-Return to Zero (NRZ) line coding. Line coding modulates the optical beam data emitted by CW Laser using Mach-Zehnder Modulator. The Selector Buffer on the OLT portion of the optical receiver receives all the upstream data by using Time Division Multiple Access (TDMA) transmitted from all ONU at the same wavelength. This wavelength is then selected using a band-pass filter, and then an APD photodetector can be used to recover the received data.

System parameters and values for hybrid CWDM/TDM-PON is shown in Table 1. The optical transmitter will be multiplexed using WDM Mux, as well as on the optical receiver will be de-multiplexed using WDM Demux. In addition, there are fiber optic component type Single Mode Fiber (SMF) and passive splitter used in this system development.

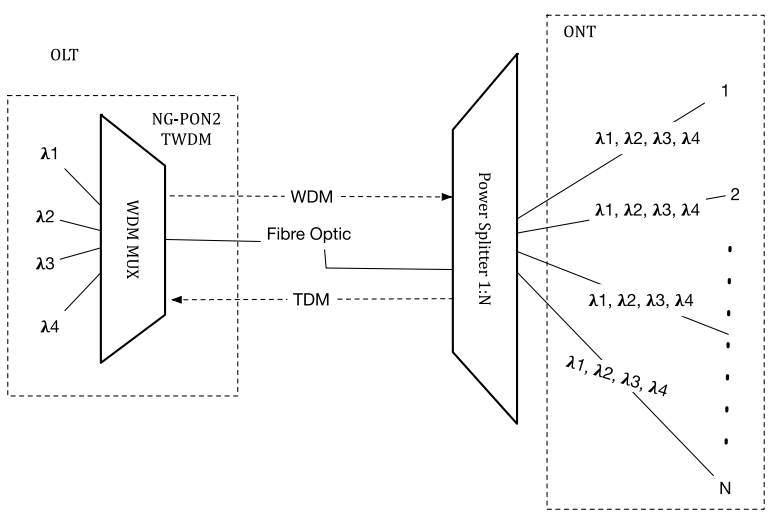

\begin{tabular}{|c|c|c|c|}
\hline \multicolumn{4}{|c|}{ PARAMETER SYSTEM } \\
\hline No & Component & Parameter & Value \\
\hline 1 & PRBS Generator & Bit rate & $10 \mathrm{Gbps}$ \\
\hline 2 & Pulse Generator & Line coding & NRZ \\
\hline 3 & Upstream & Wavelength & $1550-1610 \mathrm{~nm}$ \\
\hline & & Wavelength & $1470-1530 \mathrm{~nm}$ \\
\hline 4 & Downstream & $\begin{array}{l}\text { Power } \\
32 \text { ONU } \\
64 \text { ONU } \\
128 \text { ONU }\end{array}$ & $\begin{array}{l}4 \mathrm{dBm} \\
(10 \& 20 \mathrm{~km}) \\
5 \mathrm{dBm} \\
(10 \& 20 \mathrm{~km}) \\
5 \mathrm{dBm} \\
(10 \& 20 \mathrm{~km})\end{array}$ \\
\hline 5 & MZM Modulator & $\begin{array}{l}\text { Extinction } \\
\text { ratio }\end{array}$ & $8.2 \mathrm{~dB}$ \\
\hline \multirow{6}{*}{6} & \multirow{6}{*}{$\begin{array}{l}\text { Photodetector } \\
\text { APD }\end{array}$} & Gain & 10 \\
\hline & & Responsitivity & $0.85 \mathrm{~A} / \mathrm{W}$ \\
\hline & & $\begin{array}{l}\text { Ionization } \\
\text { ratio }\end{array}$ & 0.45 \\
\hline & & Resistance & $30 \mathrm{Ohm}$ \\
\hline & & Temperature & $298 \mathrm{~K}$ \\
\hline & & Thermal noise & $5.48 \times 10^{-12}$ \\
\hline
\end{tabular}

Figure 1. System model of hybrid CWDM/TDM-PON

TABLE 1

PARAMETER SYSTEM 
This research used the 2 stages passive splitter. There are three pairs of different number splitters that are used in this stage; 1:4 and 1:8 to form a network with 32 ONU, 1:4 and 1:16 to form a network of $64 \mathrm{ONU}$, and $1: 4$ and 1:32 to form a network of 128 ONU. The passive splitter is differentiated in number to know the quality of Hybrid CWDM / TDM-PON network to any number of existing users.

The ONU uses two devices, receivers and transmitters, where signals are received through the Bessel filter which then converts the opto-electro to the photodetector. Low pass filter (LPF) is used to carry the original signal from the modulation system. In the transmitter side, the system can generate a sequence of data from the NRZ passed from the two stages of the Dynamic Y Select device that functions as a time slot, wherein the uplink side, the data transmitted at the time slot will use the same wavelength.

The optical transmitter will be multiplexed using WDM Mux, just as the optical receiver will be demultiplexed using WDM Demux. In addition, there is also Single Mode Fiber (SMF) and passive splitter fiber optic components. Table 2 shows the parameter of optical fiber transmission media. The optical fiber serves as a transmission medium to transmit information signals in the form of propagation of light signals. The optical fiber used in this study has attenuation value $0.25 \mathrm{~dB} / \mathrm{km}$ which is shown in Table 3. This parameter is used according to the specifications of the CWDM device. This study uses a link length of $10 \mathrm{~km}$ and $20 \mathrm{~km}$. Passive splitter functions as a power divider of information sent to each user by point to multipoint method.

This research used a passive splitter with two stages (stage). This stage uses a number of different Power Splitters, namely 1: 4 and 1: 8 to form a network with 32 ONU. The number of Splitters 1: 4 and 1:16 to form a network of $64 \mathrm{ONU}$, and finally 1: 4 and 1:32 to form a 128 ONU network. This passive splitter is distinguished in number to determine the quality of the CWDM / TDMPON Hybrid network for each number of users.

The ONU uses a receiver and transmitter as well, where the signal is received through the Bessel filter which then converts the opto-electro to the photodetector. Low pass filter (LPF) is used to carry signals from the modulation results. The transmitter can produce sequences data from NRZ which is passed from two stages of Dynamic Y Select which functions as a time slot because in the uplink section the data is transmitted at the time slot using the same wavelength [7].

TABLE 2

TRANSMISSION MEDIA PARAMETER

\begin{tabular}{|c|c|c|c|}
\hline No & Devices & Parameter & Value \\
\hline \multirow[t]{6}{*}{1} & \multirow[t]{6}{*}{ Optical Fiber } & $\begin{array}{l}\text { Reference } \\
\text { Wavelength }\end{array}$ & $1550 \mathrm{~nm}$ \\
\hline & & Length & $10 ; 20 \mathrm{~km}$ \\
\hline & & Attenuation & $0.25 \mathrm{~dB} / \mathrm{km}$ \\
\hline & & Dispersion & $8 \mathrm{ps} / \mathrm{nm} \mathrm{km}$ \\
\hline & & Dispersion slope & $\begin{array}{l}0.052 \mathrm{ps} / \mathrm{nm}^{2} \\
\mathrm{~km}\end{array}$ \\
\hline & & Effective area & $63 \mu \mathrm{m}^{2}$ \\
\hline 2 & Connector & Insertion Loss & $1 \mathrm{~dB} /$ unit \\
\hline 3 & $\begin{array}{l}\text { Optical } \\
\text { Attenuator }\end{array}$ & Attenuation & $0.08 ; 0.16 \mathrm{~dB}$ \\
\hline 4 & Passive Splitter & Loss & \\
\hline
\end{tabular}

TABLE 3

OPTICAL FIBER PARAMETER

\begin{tabular}{|l|l|l|}
\hline Parameter & Value & Unit \\
\hline Reference wavelength & 1550 & $\mathrm{~nm}$ \\
\hline Attenuation & 0.25 & $\mathrm{~dB} / \mathrm{km}$ \\
\hline Dispersion & 8 & $\mathrm{ps} /(\mathrm{nm} \cdot \mathrm{km})$ \\
\hline Dispersion slope & 0.052 & $\mathrm{ps} /\left(\mathrm{nm}^{2} \cdot \mathrm{km}\right)$ \\
\hline Effective area & 63 & $\mu \mathrm{m}^{2}$ \\
\hline
\end{tabular}

Equation (5) is the formula for Dynamic Y Select 1 for 16 time slots.

$$
S E T=T s \cdot \frac{1}{B r} \cdot \frac{\text { Seq_length }}{16},
$$

and (6) is the formula for Dynamic Y Select 2 for 16 time slots.

$$
S E T=T S \cdot \frac{1}{B r} \cdot \frac{\text { Seq_length }}{16} \cdot \frac{T w}{16},
$$

where SET is Switching Event Time, $T s$ is time slot and $\mathrm{Tw}$ is Time Window and $\mathrm{Br}$ is bit rate. The advantages of time domain are able to deliver uplink data without using different wavelength. Several ONU with different request to OLT can be fulfilled using serial time domain. In this paper, we use the number of ONU up to 128 and if they access OLT simultaneous, they give timeslot where the number of time slots is 16 .

\section{Hybrid CWDM/TDM-PON for $32 \mathrm{ONU}$}

A scenario for 32 ONU in Figure 2 uses two passive splitter stages, namely 1:4 and 1:8. The wavelength used on the transmission side of the downstream direction is $\left(\lambda_{1}, \lambda_{2}, \lambda_{3}, \lambda_{4}\right)$ while the wavelength used on the transmission side of the upstream direction is $\left(\lambda_{5}, \lambda_{6}, \lambda_{7}\right.$, $\left.\lambda_{8}\right)$. The wavelength $\left(\lambda_{1}, \lambda_{2}, \lambda_{3}, \lambda_{4}\right)$ represents the OLT scheme modeling, while the wavelength $\left(\lambda_{5}, \lambda_{6}, \lambda_{7}, \lambda_{8}\right)$ represents the $\mathrm{ONU}_{1-8}$ modeling scheme in the simulation. WDM MUX / DEMUX is used for wavelength multiplexing / demultiplexing processes so it can transmit data from all wavelengths to one fiber optic channel.

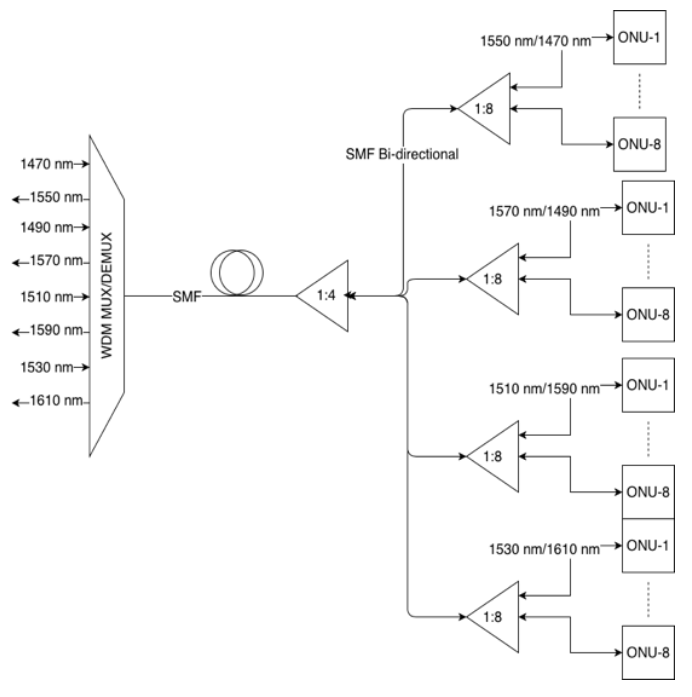

Figure 2. Model System 32 ONU 
Information signal transmission is done using Bidirectional SMF type of optical fiber transmission media. On the transmission side, the downstream direction uses data capacity of $10 \mathrm{Gbps}$ at each wavelength, while on the transmission side upstream direction uses data capacity of $2.5 \mathrm{Gbps}$ at each wavelength. So the CWDM / TDM-PON Hybrid system produces a bit rate of $40 / 10 \mathrm{Gbps}$.

\section{Hybrid CWDM/TDM-PON for $32 \mathrm{ONU}$}

A scenario for 64 in Figure 3 uses two passive splitter stages, namely 1:4 and 1:16. The wavelength used on the transmission side of the downstream direction is $\left(\lambda_{1}, \lambda_{2}, \lambda_{3}, \lambda_{4}\right)$ while the wavelength used on the transmission side of the upstream direction is $\left(\lambda_{5}, \lambda_{6}, \lambda_{7}\right.$, $\left.\lambda_{8}\right)$. The wavelength $\left(\lambda_{1}, \lambda_{2}, \lambda_{3}, \lambda_{4}\right)$ represents the OLT scheme modeling, while the wavelength $\left(\lambda_{5}, \lambda_{6}, \lambda_{7}, \lambda_{8}\right)$ represents the $\mathrm{ONU}_{1-16}$ modeling scheme in the simulation. The process of sending information signals in the scenario for $32 \mathrm{ONU}$ is the same as the scenario for 64 ONU.

\section{E. Hybrid CWDM/TDM-PON for $128 \mathrm{ONU}$}

A scenario for 128 in Figure 4 uses two passive splitter stages, namely 1:4 and 1:32. The wavelength used on the transmission side of the downstream direction is $\left(\lambda_{1}, \lambda_{2}, \lambda_{3}, \lambda_{4}\right)$ while the wavelength used on the transmission side of the upstream direction is $\left(\lambda_{5}, \lambda_{6}, \lambda_{7}\right.$, $\left.\lambda_{8}\right)$. The wavelength $\left(\lambda_{1}, \lambda_{2}, \lambda_{3}, \lambda_{4}\right)$ represents the OLT scheme modeling, while the wavelength $\left(\lambda_{5}, \lambda_{6}, \lambda_{7}, \lambda_{8}\right)$ represents the $\mathrm{ONU}_{1-16}$ modeling scheme in the simulation. The process of sending information signals in the scenario for 32 and $64 \mathrm{ONU}$ is the same as the scenario for $128 \mathrm{ONU}$.

\section{F. Rise Time Budget}

In this research, it is necessary to calculate the rise time budget to ensure that the network can be simulated or implemented. The rise time budget is a consideration of the limits of tolerability of dispersions that are allowed. Passing a certain dispersion limit, an optical link does not meet. The dispersion that occurs in the calculation of the optical link must always be lower than the time bit limit. Below are the calculation and the calculation stage of the rise time budget for the three numbers of ONU.

The calculation of rise time budget hybrid CWDM / TDM-PON for downstream and upstream at $10 \mathrm{~km}$ and $20 \mathrm{~km}$ long links is done at each wavelength by changing the material dispersion according to the used wavelength. The rise time budget vs. wavelength dispersion is shown in Figure 5.

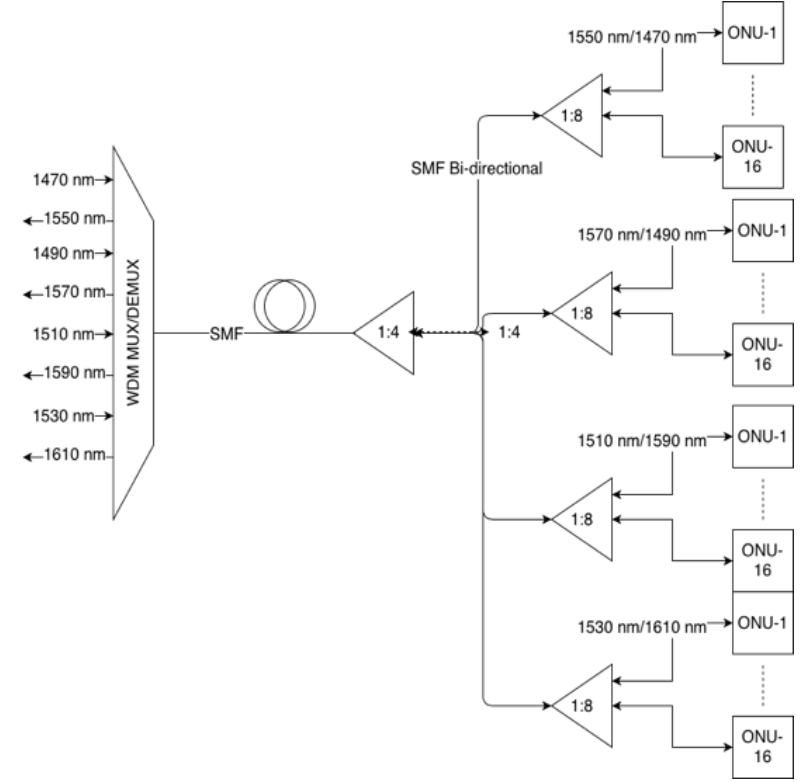

Figure 3. Model System 64 ONU

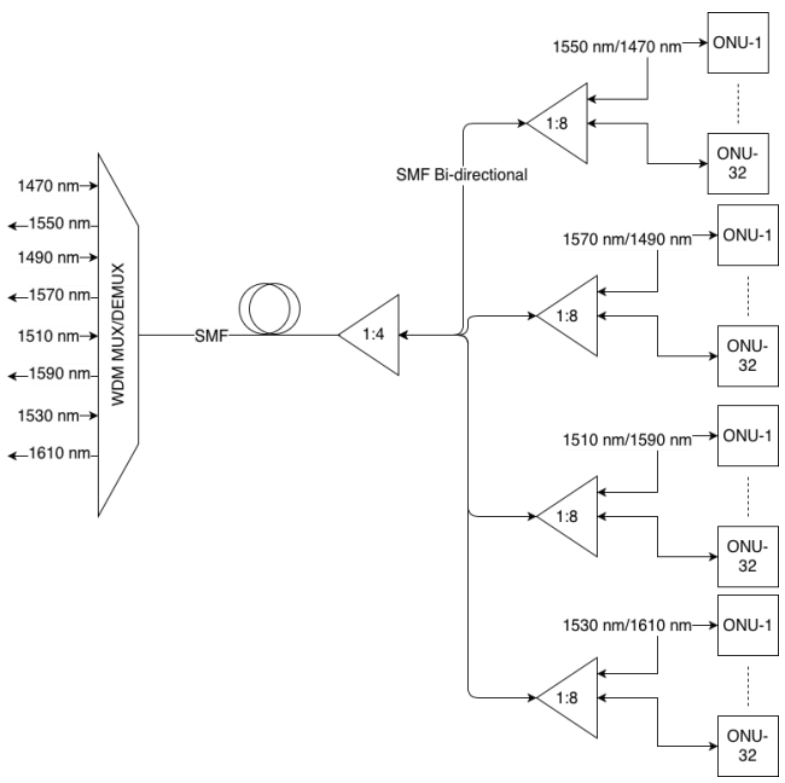

Figure 4. Model System 128 ONU

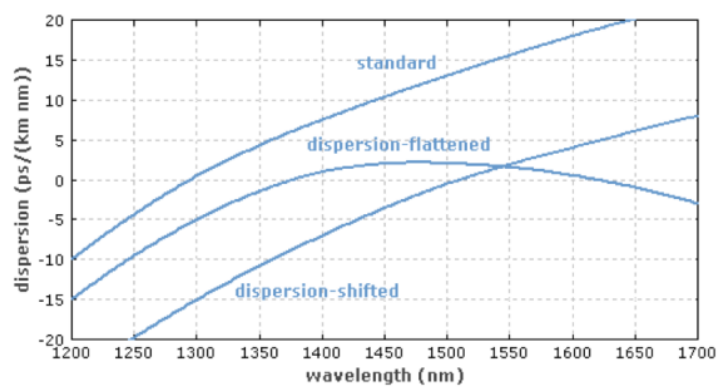

Figure 5. Wavelength dispersion [8] 


\section{1) RTB $10 \mathrm{~km}$ cable length}

The Rise Time Budget Hybrid calculation for CWDM / TDM-PON for downstream and upstream at 10 $\mathrm{km}$ link length with bit rate $10 \mathrm{Gbps}$ is as follow.

\section{Downstream 10 km (1550 nm)}

$t_{s y s}=\sqrt{t_{T x}^{2}+t_{r x}^{2}+t_{m a t}^{2}}$

$t_{T x}=30 \mathrm{ps}$

$t_{R x}=30 \mathrm{ps}$

$B_{r}=1 \times 10^{10} \mathrm{bps}$

$t_{\text {Trans }}=\frac{0.7}{B_{r}}=\frac{0.7}{10^{10}}$

$t_{\text {Trans }}=70 \mathrm{ps}$

$t_{\text {mat }}=20 \times 10 \times 0.013$

$\mathrm{t}_{\text {mat }}=2.6 \mathrm{ps}$

$t_{\text {sys }}=\sqrt{30^{2}+30^{2}+2.2^{2}}$

$t_{\text {sys }}=42.506 \mathrm{ps}$

\section{Upstream $10 \mathrm{~km}(1610 \mathrm{~nm})$}

$t_{s y s}=\sqrt{t_{T x}^{2}+t_{r x}^{2}+t_{m a t}^{2}}$

$t_{T x}=30 \mathrm{ps}$

$t_{R x}=30 \mathrm{ps}$

$B_{r}=2.5 \times 10^{9} \mathrm{bps}$

$t_{\text {Trans }}=\frac{0.7}{B_{r}}=\frac{0.7}{2.5 \times 10^{9}}$

$t_{\text {Trans }}=280 \mathrm{ps}$

$t_{\text {mat }}=20 \times 10 \times 0.0185$

$\mathrm{t}_{\text {mat }}=3.7 \mathrm{ps}$

$t_{\text {sys }}=\sqrt{30^{2}+30^{2}+3.7^{2}}$

$t_{\text {sys }}=42.587 \mathrm{ps}$

For 10 Gbps with NRZ Coding Line, the rise time value is $70 \mathrm{~ns}$. For $2.5 \mathrm{Gbps}$ the rise time value is $280 \mathrm{~ns}$. The calculation above shows that the Rise Time Budget for downstream and upstream with a $10 \mathrm{~km}$ link length is qualified because it has a smaller value than the initial rise time.

2) RTB $20 \mathrm{~km}$ cable length

The Rise Time Budget Hybrid calculation for CWDM / TDM-PON for downstream and upstream at 20 $\mathrm{km}$ link length with bit rate $10 \mathrm{Gbps}$ is as follow.

\section{Downstream 20 km (1550 nm)}

$t_{\text {sys }}=\sqrt{t_{T x}^{2}+t_{r x}^{2}+t_{m a t}^{2}}$

$t_{T x}=30 \mathrm{ps}$

$t_{R x}=30 \mathrm{ps}$

$B_{r}=1 \times 10^{10} \mathrm{ps}$

$t_{\text {Trans }}=\frac{0.7}{B_{r}}=\frac{0.7}{10 \times 10^{9}}$

$t_{\text {Trans }}=70 \mathrm{ps}$

$t_{\text {mat }}=20 \times 20 \times 0.0185$

$\mathrm{t}_{\text {mat }}=5.2 \mathrm{ps}$

$t_{s y s}=\sqrt{30^{2}+30^{2}+5.2^{2}}$

$t_{\text {sys }}=42.744 \mathrm{ps}$

\section{Upstream 20 km (1610 nm)}

$t_{s y s}=\sqrt{t_{T x}^{2}+t_{r x}^{2}+t_{m a t}^{2}}$

$t_{T x}=30 \mathrm{ps}$

$t_{R x}=30 \mathrm{ps}$

$B_{r}=2.5 \times 10^{10} \mathrm{ps}$

$t_{\text {Trans }}=\frac{0.7}{B_{r}}=\frac{0.7}{2.5 \times 10^{9}}$

$t_{\text {Trans }}=280 \mathrm{ps}$

$t_{\text {mat }}=20 \times 20 \times 0.0185$

$\mathrm{t}_{\text {mat }}=7.4 \mathrm{ps}$

$t_{\text {sys }}=\sqrt{30^{2}+30^{2}+7,4^{2}}$

$t_{\text {sys }}=43.067 \mathrm{ps}$

For $10 \mathrm{Gbps}$ with NRZ Coding Line, the rise time value is $70 \mathrm{~ns}$. For $2.5 \mathrm{Gbps}$ the rise time value is $280 \mathrm{~ns}$. The calculation above shows that the Rise Time Budget (RTB) for downstream and upstream with a $20 \mathrm{~km}$ link length is qualified because it has a smaller value than the initial rise time.

\section{RESULTS AND DISCUSSION}

\section{A. Research on dual distance}

The Hybrid CWDM / TDM-PON system model in the first scenario uses 2 passive splitter steps, 1:4 and 1:8 passive splitter that has attenuation $6.02 \mathrm{~dB}$ and $9.03 \mathrm{~dB}$ respectively. This scenario with a 1:32 ONU passive splitter uses $10 \mathrm{~km}$ and $20 \mathrm{~km}$ cable lengths and uses a 4 $\mathrm{dBm}$ power output laser for both downstream and upstream directions.

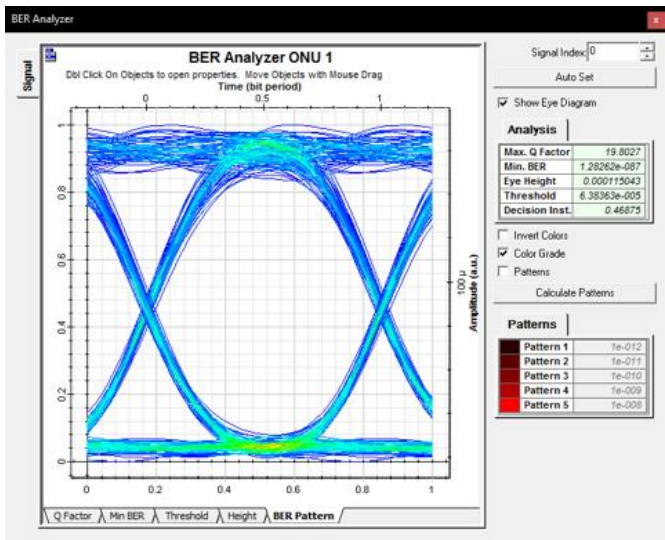

Figure 6. The eye diagram for $32 \mathrm{ONU}$ in $10 \mathrm{~km}$

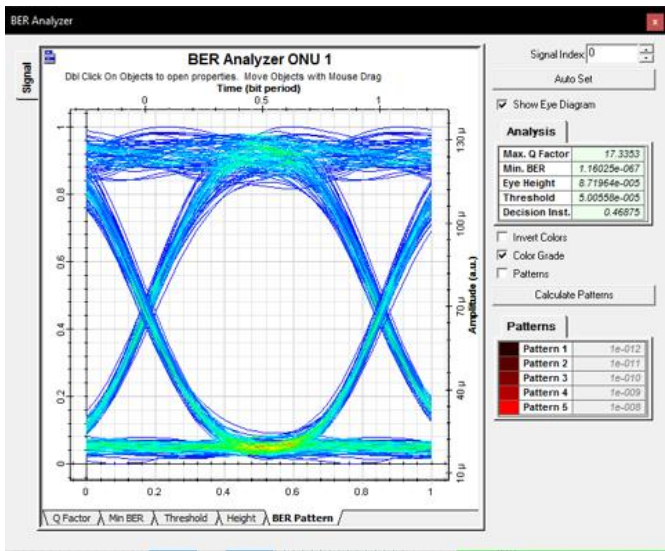

Figure 7. The eye diagram for $64 \mathrm{ONU}$ in $10 \mathrm{~km}$ 
Figure 6 shows the simulation result for $32 \mathrm{ONU}$ in $10 \mathrm{~km}$. The figure also shows values of $\mathrm{Q}$-factor and BER. The final results of the first scenario with cable length of 10 and $20 \mathrm{~km}$ have a value of Q-Factor 25.960 and 14.815 respectively. The CWDM / TDM-PON Hybrid system model in the second scenario uses 2 passive splitter steps, 1:4 and 1:16 passive splitters that have attenuation $6.02 \mathrm{~dB}$ and $12.04 \mathrm{~dB}$ respectively. This scenario with 1:64 ONU passive splitter is done with a cable length of 10 and $20 \mathrm{~km}$ using laser output power of $5 \mathrm{dBm}$ for downstream and upstream direction.

The simulation result for 64 ONU in $10 \mathrm{~km}$ is depicted in Figure 7. The result of a second scenario with the same cable length has a Q-Factor value of 15.808 and 13.046 respectively. The CWDM / TDM-PON Hybrid system model in the third scenario uses two passive splitter steps, ie 1: 4 and 1:32 passive splitters with a sequential attenuation value of $6.02 \mathrm{~dB}$ and $15.05 \mathrm{~dB}$. This scenario with 1: 128 ONU passive splitter is done with a cable length of 10 and $20 \mathrm{~km}$ using $5 \mathrm{dBm}$ laser output power for downstream and upstream direction.

Figure 8 shows the simulation result for $128 \mathrm{ONU}$ in $10 \mathrm{~km}$. The results of the second scenario with the same cable length have the value of Q-Factor of 17.778 and 12.944 successively. Table 4 describes the summary of simulation results in the value of Q-Factor. The word "DS" means Downstream and "US" means Upstream. In this paper, all Q-Factors are conformed to the ITU-T standard. Thus, all scenarios in the CWDM-TDM hybrid can be applied to the NG-PON2 network.

\section{B. Research on variations in distance}

This research produced a graph of the experiment to change the spacing of more detailed research distances. In the beginning, research was produced from two distances, 10 and $20 \mathrm{~km}$. In this sub-chapter, changes in distance are smaller so that trend changes are clearer to be analyzed.

After we found the difference between the distance of $10 \mathrm{~km}$ and $20 \mathrm{~km}$, the paper continued to find the limit of the farthest distance. In the optical network standard [9], it can be seen that the quality standard is 6 for the Qfactor parameter. From the simulation results, the performance of each number of ONU is found, and the maximum length difference is achieved.

Figure 9 illustrates the comparison of the number of different receivers, 32 ONU, 64 ONU, and $128 \mathrm{ONU}$. The maximum cable length is achieved by the number of $32 \mathrm{ONU}$ that is around $40 \mathrm{~km}$, while the number of 64 ONU is at a distance of $30-35 \mathrm{~km}$, and a maximum distance of 128 ONU ranges from $25-30 \mathrm{~km}$. The distance achieved when each number of ONUs gets a Qfactor value is 6 .

In calculating and simulating the power budget link, it is certain that each power splitter produces a progressive loss. The more power splitter used to divide the power for the receiver, the lower the power received. Low power received affects the distance traveled by laser power.
TABLE 2

Q-FACTOR OF THE SIMULATION RESULT

\begin{tabular}{|c|l|l|l|l|}
\hline \multirow{2}{*}{ Length $(\mathrm{km})$} & \multirow{2}{*}{ Direction } & \multicolumn{3}{|c|}{ Q-Factor } \\
\cline { 3 - 5 } & & 32 ONU & 64 ONU & 128 ONU \\
\hline \multirow{2}{*}{10} & DS & 19.803 & 17.335 & 11.969 \\
\cline { 2 - 5 } & US & 19.963 & 17.470 & 12.091 \\
\hline \multirow{2}{*}{20} & DS & 18.105 & 12.219 & 11.048 \\
\cline { 2 - 5 } & US & 15.215 & 11.226 & 11.148 \\
\hline
\end{tabular}

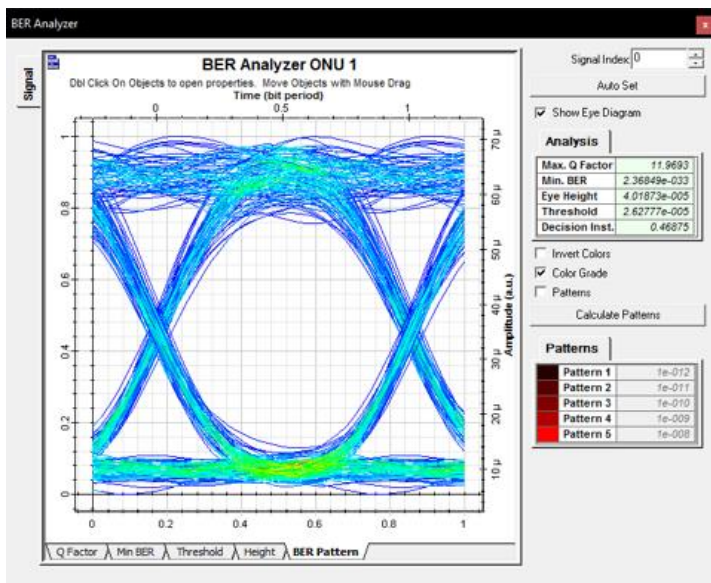

Figure 8 . The eye diagram for $128 \mathrm{ONU}$ in $10 \mathrm{~km}$

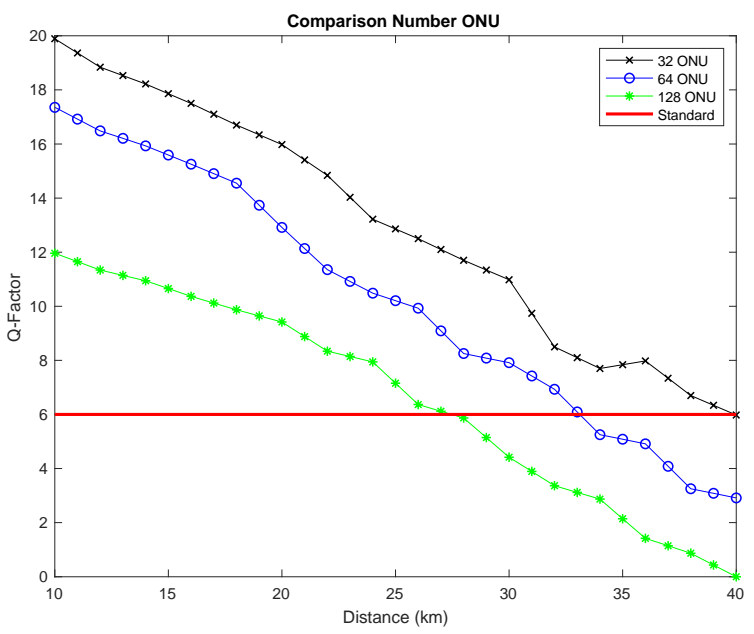

Figure 9. Chart of various numbers of $\mathrm{ONU}$

\section{Conclusion}

In this paper, CWDM / TDM-PON Hybrid on NGPON2 can be considered that CWDM / TDM-PON Hybrid network is capable of NG-PON2 technology with bit rate of 40/10 Gbps with a cable length of 10 and 20 $\mathrm{km}$. The results of simulation and analysis in the first scenario, with a cable length of $10 \mathrm{~km}$ resulted in a difference of Q-Factor value of 6.157 or about $31.09 \%$. The value of Q-Factor on passive splitter $32 \mathrm{ONU}$ is able to reach maximum value at cable length $40 \mathrm{~km}$, which is equal to 6.62 . 
The results of simulation and analysis in the second scenario that used cable length of $10 \mathrm{~km}$ resulted in the difference of the value of Q-Factor, 1.527 or about $8.81 \%$. The value of Q-Factor on passive splitter $64 \mathrm{ONU}$ is able to reach maximum value at cable length $32.5 \mathrm{~km}$, equal to 6.288. Results of analysis and simulation in the third scenario, $10 \mathrm{~km}$ cable length resulted in the difference of Q-Factor value, 5.809 or about $48.53 \%$. QFactor value on passive splitter $128 \mathrm{ONU}$ is able to achieve maximum value at $23.5 \mathrm{~km}$ link length of 6.859 .

This research can still be developed on the side of scalability, where the number of users added and the length of the cable expanded. Thus, a parameter can be achieved for NG-PON2 with an optimal scalability value.

\section{REFERENCES}

[1] K. Khairi, Z. A. Manaf, D. Adriyanto, M. Salleh, Z. Hamzah and R. Mohamad, "CWDM PON system: next generation PON for access network," in IEEE 9th Malaysia International Conference on Communications (MICC), 2009.

[2] B. Pamukti and D. Perdana, "Performance Evaluation of DCF Length for High Scalability NG-PON2," Telkomnika, vol. 15, no. 1, p. 165,2017
[3] M. Abdullah, B. Das and M. S. N. Shahida, "Frequency domain technique for reducing chromatic dispersion," in Electrical Power, Electronics, Communications, Controls and Informatics Seminar (EECCIS), Malang, 2014.

[4] M. D. Mrakovi'c and P. S. Matavulj, "Analysis of coexisting GPON and NG-PON1 (10G-PON) systems," Telfor Journal, vol. 3 , no. 1 , pp. 43-48, 2011

[5] A. Hambali and A. Syahriar, "Analisa Karakteristik Gain Serat Optik Erbium Doped Amplifier Mode Tunggal," In Proc. of Komputer dan Sistem Intelijen (KOMMIT), 2003.

[6] B. Pamukti, D. Perdana and M. Kirom, "Thermal effect analysis of arrayed waveguide grating in NG-PON2 network," Engineering Letters, vol. 26, no. 2, 2018.

[7] D. Astharini, A. Mayola, O. N. Samijayani and Ary Syahriar, "Analisa Kinerja Teknik Modulasi Digital pada Kanal Optik Nirkabel," Jurnal Elektronika dan Telekomunikasi, vol. 17, no. 1, pp. 7-12, 2017.

[8] "RP Photonics," [Online]. Available: https://www.rpphotonics.com/dispersion_shifted_fibers.html. [Accessed 21 August 2018]

[9] "Q-factor test equipment to estimate the transmission performance of optical channels," 2003.

[10] LUO, Yuanqiu, et al., "Physical layer aspects of NG-PON2 standards-Part 2: System design and technology feasibility," Journal of Optical Communications and Networking, vol. 8, no. 1, pp. 43-52, 2016. 